
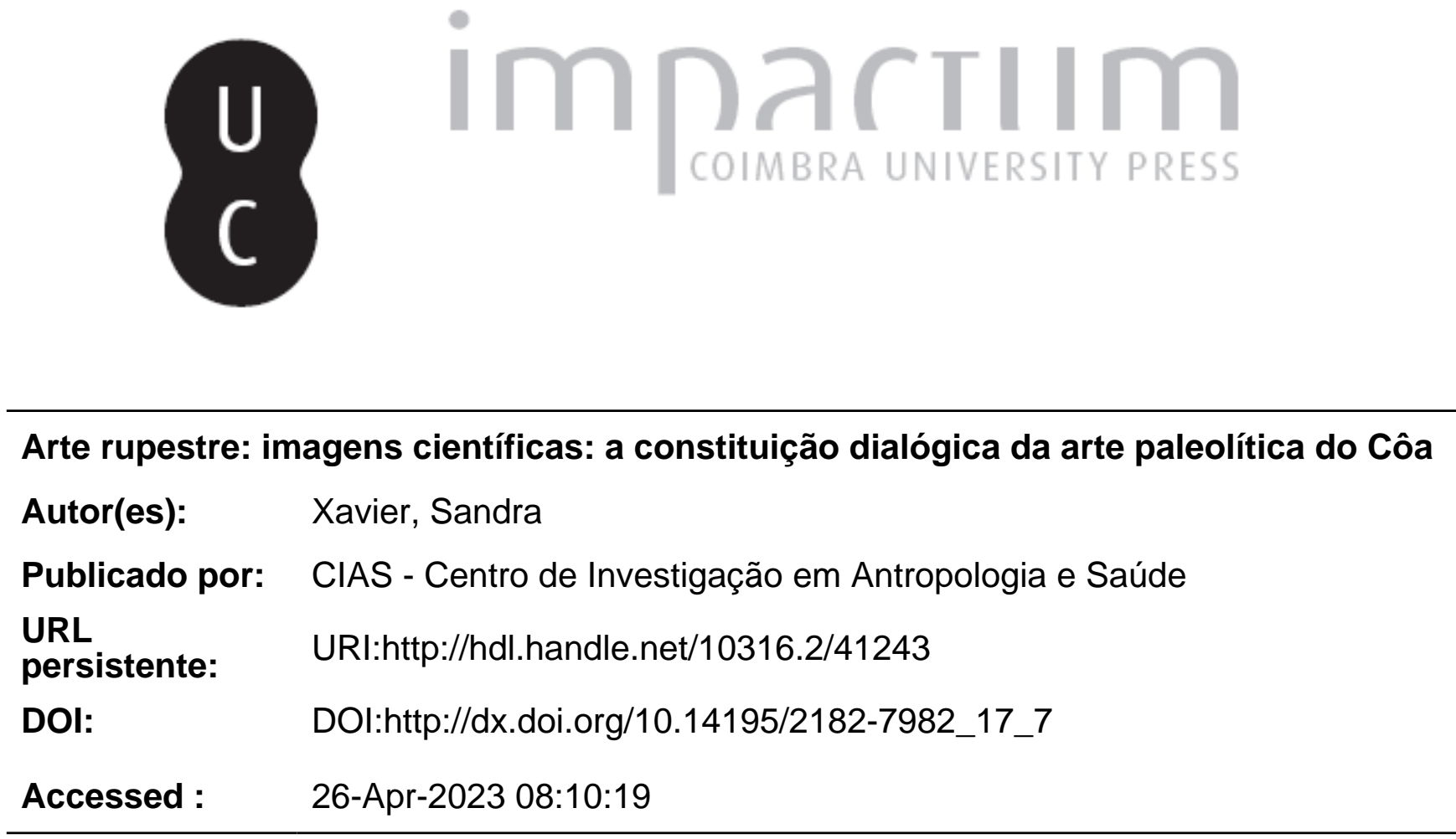

A navegação consulta e descarregamento dos títulos inseridos nas Bibliotecas Digitais UC Digitalis, UC Pombalina e UC Impactum, pressupõem a aceitação plena e sem reservas dos Termos e Condições de Uso destas Bibliotecas Digitais, disponíveis em https://digitalis.uc.pt/pt-pt/termos.

Conforme exposto nos referidos Termos e Condições de Uso, o descarregamento de títulos de acesso restrito requer uma licença válida de autorização devendo o utilizador aceder ao(s) documento(s) a partir de um endereço de IP da instituição detentora da supramencionada licença.

Ao utilizador é apenas permitido o descarregamento para uso pessoal, pelo que o emprego do(s) título(s) descarregado(s) para outro fim, designadamente comercial, carece de autorização do respetivo autor ou editor da obra.

Na medida em que todas as obras da UC Digitalis se encontram protegidas pelo Código do Direito de Autor e Direitos Conexos e demais legislação aplicável, toda a cópia, parcial ou total, deste documento, nos casos em que é legalmente admitida, deverá conter ou fazer-se acompanhar por este aviso. 


\section{Antropologia Portuguesa}

$16-17 \cdot 1999-2000$

Departamento de Antropologia | Universidade de Coimbra 


\title{
Arte Rupestre - Imagens Científicas: a constituição dialógica da arte paleolítica do Côa
}

\author{
Sandra Xavier \\ Departamento de Antropologia \\ Universidade de Coimbra \\ 3000-056 Coimbra, Portugal \\ sandrax@ci.uc.pt
}

\section{Resumo}

Este artigo recorre à noção de estória dialógica apresentada por Edward Bruner e Phyllis Gorfain para pensar os processos sociais e políticos que se encontram subjacentes à descoberta arqueológica das gravuras paleolíticas do vale do Côa. Procura-se demonstrar como os discursos sobre as gravuras foram produzidos no interior da comunidade arqueológica, em interacção com discursos por ela anteriormente elaborados, difundidos e suportados, e, em particular, com os de LeroiGourhan, inseridos numa narrativa sobre a história da disciplina que os legitima, e respondem às versões alternativas que se lhes opõem - neste caso, aos discursos dos especialistas em datação absoluta sobre a cronologia pós-paleolítica das gravuras. Conferindo especial atenção aos processos de visualização, este artigo procura também demonstrar como se constituiram as imagens científicas das gravuras do Côa que estruturam a sua de (per si) difícil percepção.

\section{Palavras-chave}

Arte rupestre, percepção, discursos científicos, arqueologia portuguesa, Vale do Côa

\section{Abstract}

This article is based on the utilisation of Edward Bruner and Phyllis Gorfain's notion of dialogic narration to consider the social and political processes behind the discovery of paleolithic petroglyphs in the Côa valley. The discourses about the petroglyphs were constituted within the arqueological community, in relation to discourses previously uttered, and especially in relation to the interpretations of André Leroi-Gourhan. However, they have been also constituted in the relation to alternative stories; for example in opposition to the discourses that date the 
petroglyphs to recent times. This article gives special attention to the processes of visualization and the construction of scientific images that inform our perception of Côa petroglyphs.

\section{Key words}

Rock art, perception, cientific discourses, Portuguese archeology, Côa Valley

\section{A invisibilidade reiterada}

Quando, no Verāo de 1995, visitei pela primeira vez o vale do Côa, na procura de gravuras paleolíticas aí recentemente descobertas, deparei-me com a perplexidade de um homem que me dizia ter nascido numa aldeia próxima. Contava que ao longo da sua vida sentara-se inúmeras vezes junto da fraga na qual diziam, agora, existirem gravuras inscritas, reconhecendo, desorientado, nunca as ter visto. Um ano mais tarde, no decorrer do meu trabalho de campo, eu viria a deparar-me com a mesma e reiterada afirmação. As gravuras tão noticiadas nos diversos órgãos de comunicação social nunca tinham sido visualizadas pelos habitantes de Muxagata. E ainda hoje muitas destas pessoas não as conseguem ver. A possibilidade de ver estas imagens não é portanto imediata, evidente, igualmente acessível a todos. Mas, ao contrário, e como procurarei aqui demonstrar, a visualização das gravuras paleolíticas do Côa foi constituída através de métodos, técnicas e/ou discursos produzidos no interior da comunidade científica dos arqueólogos'.

Ao longo de toda a Idade Moderna, o pensamento científico reclamou para si uma racionalidade a-histórica, a-social, a-cultural e a-política. Ignorava as suas próprias condições sociais de produção para poder afirmar a validade universal dos seus pressupostos. Baseou-se na dicotomia cartesiana entre a res extensa e o ego cogitans e, assim, garantiu a

${ }^{3}$ A visualizaçāo das gravuras paleolíticas do Côa, sendo socioculturalmente específica à comunidade dos arqueólogos, instituiu-se como o fundamento de uma nova apropriação do território, materilizada na construção do Parque Arqueológico do Vale do Côa. A criação do parque arqueológico implicou assim disputas e conflitos com outras configuraçōes do espaço-tempo. Ao permanecer durante quatro meses numa das aldeias incluj́das no Parque, procurei então compreender como o espaço era aí socioculturalmente construído (ver Xavier 1999 e 2000). 
independência do mundo físico e natural face aos sistemas social e culturalmente organizados. As ciências naturais conseguiram retirar os enunciados sobre o mundo do seu contexto social e afirmar a sua autonomia por relação às ciências sociais e humanas. Hoje, questiona-se a dicotomia cartesiana, multiplicam-se os estudos de ciência, a história da ciência ocupa um lugar de destaque entre as ciências sociais, e a análise das condiçōes sociais de produção e difusão do conhecimento científico é cada vez mais frequente. É no interior deste contexto que deve ser inserido o meu argumento.

Para tentar compreender os processos sociais de produção, aceitação e difusão dos discursos arqueológicos sobre as gravuras paleolíticas do Côa, irei recorrer à noção de estória dialógica tal como ela é empregue por Edward Bruner e Phyllis Gorfain (1984). Estes dois autores, influenciados por Mikhail Bakhtin, consideram que uma estória (ou se quisermos uma narrativa ou um discurso) é produzida dialogicamente - em interacção com um "outro" - no interior de um determinado contexto sociocultural. "[W]e argue that a story cannot be viewed in isolation, as a monologic static entity, but must be seen in a dialogic or interactive framework" (Bruner e Gorfain 1984: 57). Um dado discurso interage, por exemplo, com os discursos anteriores, com a história e a sua formulação narrativa e com discursos alternativos e críticos que se lhe opõem (cf. Idem: 60, 66). "Dialogic narration is not simply a dialogue or a debate but a polyphonic discourse based on tellings, retellings, or references to important cultural narratives. Any particular telling of the (...) story then resonates against previous and future tellings, against its own past centuries (...), against metonymic sites, (...), and against stories that embody alternatives" (idem: 68). Bruner e Gorfain inserem um discurso no interior de uma tradição discursiva e de uma dada comunidade, mas estes sāo concebidos como um "outro" com o qual o discurso se relaciona dialogicamente de uma forma processual e plural. "Our aim, then, is to develop the concept of dialogic narration, to contribute to narrative theory by introducing a processual perspective, and to root the narrative process in a society without reducing it to a mere reflection of society" (idem: 60). Defensores de diferentes versões da realidade, competem entre si pelo espaço discursivo, pelo direito a contar a estória (cf. idem: 60). Bakhtin, e com ele Bruner e Gorfain, defende que existem versões da estória (ou se quisermos da realidade) autorizadas, com uma autoridade que lhes advém da posição do- 
minante do seu narrador no interior da comunidade e da tradição narrativa que a sustém.

The 'authoritative' in this view is not inherent in some cuthoritative version of the story but in the authoritative positions of tellers within a community, in the interaction between a performance situated within a locus of power and one offered on the boundaries of public structures. In Bakhtin's words, the 'authoritative' is the 'already uttered'; it is 'prior discourse', backed by legal, political and moral authority (idem: 59).

No entanto, a autoridade do discurso e do seu narrador, a aceitação daquele e a credibilidade deste, nem sempre estão preestabelecidas ou preexistem à polémica, confronto e competição pelo espaço discursivo. As versōes autorizadas e as versões desacreditadas não permanecem as mesmas ao longo do tempo, nem estão definidas antes do confronto entre as diferentes versões - elas são, ao contrário, estabelecidas processualmente. Como Bruner e Gorfain reconhecem, a versão que hoje desafia a versão autorizada pode, mais tarde, vir a tornar-se na versão dominante (cf. idem: 70).

Recorrer à noção de estória ou discurso dialógico para tentar perceber como os enunciados científicos são produzidos e aceites, é tentar desvendar os processos sociais e políticos que se lhe encontram subjacentes e, assim, tratá-los como quaisquer outros enunciados ou proposições culturalmente construídas. É verdade que (como veremos) as comunidades científicas têm regras específicas de enunciação e validação, que, aliás, servem para constantemente definir o que é e o que não é científico e, assim, quem faz e quem não faz parte dessa comunidade. No entanto, e sem querer avaliar a adequação das proposições científicas ao mundo (pois não é isso que me interessa), penso ser indiscutível que o conhecimento científico é produzido em contextos de interacção cujos processos sociais e políticos podem ser legitimamente analisados. Neste sentido, a oposição cartesiana entre a res extensa e o ego cogitans tornouse desadequada. Os enunciados sobre o mundo não são independentes do contexto social no qual são produzidos e as ciências naturais perdem a sua autonomia por relação às ciências sociais.

Também a oposição mente/corpo, subjacente à dicotomia cartesiana, é aqui questionada. Da res extensa faziam parte o corpo e os estímulos 
sensoriais que, sendo quantificáveis, forneciam um fundamento seguro e objectivo ao conhecimento científico. Só posteriormente os dados fornecidos pelos sentidos seriam subjectivamente e pela consciência interpretados. A dicotomia cartesiana opunha assim a percepção, incluída na res extensa, à interpretação, associada ao ego cogitans. Em 1945, A Fenomenologia da Percepção insurge-se contra estas dicotomias. Para MerleauPonty não há sensações puras, isoladas, reacçōes a estímulos indiferenciados, instantâneos e pontuais, mas qualquer percepção, por mais elementar que seja, é já um todo organizado e dotado de sentido. "Chaque partie annonce plus qu'elle ne contient et cette perception élémentaire est donc déjà chargée d'un sens" (Merleau-Ponty 1945: 9). O aparelho sensorial não é apenas físico, mecânico, um transmissor de mensagens sobre o mundo exterior, mas um sujeito que relaciona e estrutura o sensível. Ou seja, já não podemos opor a percepção, pensada como física, à razão que relaciona, constitui e conhece. "Le sensible est ce qu'on saisit avec les sens, mais nous savons maintenant que cet «avec» n'est pas simplement instrumental, que l'appareil sensoriel n'est pas un conducteur, que même à la périphérie l'impression physiologique se trouve engagée dans des relations considérées autrefois comme centrales" (idem: 17).

Se a percepção é já um todo dotado de sentido então ela não se manifesta do mesmo modo em todo e qualquer sujeito. Na verdade, autores como Constance Classen (1993) e Paul Stoller (1989) têm vindo a demonstrar como os sentidos são culturalmente organizados. $O$ que me interessa, portanto, demonstrar através deste artigo é como a percepção e a visualização das gravuras paleolíticas do Côa (e não apenas a sua interpretação e classificaçāo), foi constituída no interior da comunidade científica dos arqueólogos e em interacção com a tradição discursiva que a sustém. Neste sentido, não nos podemos admirar pelo facto de as gravuras não terem sido percepcionadas por quem se encontrava no exterior desta comunidade e não tinha acesso, de uma ou de outra forma, à tradição discursiva em que ela se funda.

Já que as gravuras paleolíticas do Côa foram constituídas em interacção com a tradição de pensamento da arqueologia, ainda antes de falar do processo social da sua constituição, farei uma breve referência ao modo como a arte rupestre tem sido pensada pela arqueologia desde o momento em que, nos finais do século XIX, se instituiu como objecto arqueológico. Pretendo demonstra como certas oposições, tensões e polé- 
micas que marcaram a história de arte pré-histórica se reproduziram nos discursos sobre as gravuras do Côa, sem, no entanto, pretender encontrar ou definir a versão verdadeira sobre a história da arte rupestre.

\section{Como se tornou a arte rupestre num objecto arqueológico?}

Desde o princípio da história da arqueologia que nela se confrontam dois modelos distintos e irredutíveis de descrição, classificação e análise das sociedades pré-históricas (ver Zilhão 1991). O evolucionismo do século XIX e a "nova arqueologia" dos anos 60 do século XX, marcados pelo positivismo, seguem o modelo epistemológico das ciências naturais, procurando as leis universais que, independentemente da cultura, explicam o comportamento humano. Ao pensar os achados pré-históricos através de estratégias de subsistência e de adaptação ecológica que anulam os seus aspectos simbólicos, a "nova arqueologia" utiliza, para os analisar, o quadro teórico das ciências ecológicas e, mais especificamente, da socioecologia dos primatas ${ }^{2}$. No outro lado, encontra-se uma leitura mais humanizadora das sociedades pré-históricas, representada pela "história das culturas" e pelas perspectivas "pós-processuais", que enfatiza as dimensōes culturais e simbólicas. Ela procura conhecer através dos achados a cultura particular na qual eles se inseriam.

Ao olharmos para a história da arqueologia podemos ver também como, na Europa, a arqueologia se liga à história e insere os achados num passado genealogicamente relacionado com o presente. Tradicionalmente ligada à descoberta do passado e das origens, ela está preocupada com a dataçāo e periodização dos achados, em ordená-los através do eixo do tempo. Ao passo que, no continente americano, as periodizações históricas tornam-se irrelevantes para a arqueologia e, particularmente, para a "nova arqueologia" que compreende e classifica os achados através de áreas geográficas ou ecológicas.

2 Associada a esta interpretação estritamente ecológica dos achados pré-históricos não estará a constituiçāo de uma representação do homem pré-histórico que o aproxima da natureza e o julga incapaz de pensamento simbólico? 
A entrada, no final do século XIX, da arte rupestre no domínio de investigação dá Arqueologia europeia esteve, portanto e por um lado, dependente da aceitação da sua origem pré-histórica, já que na Europa a arqueologia se mantinha ligada ao estudo do passado remoto. Por outro lado, a aceitação da origem pré-histórica da arte rupestre dependia da defesa de uma visão mais humanista e humanizadora das sociedades préhistóricas que se opunha àquela que as aproximava da natureza.

Acompanhemos então o processo através do qual a arte rupestre se constituiu como um objecto de estudo da arqueologia europeia.

Algumas pinturas, como as de Niaux e Rouffignac, já eram conhecidas há muito tempo. Delas encontramos descrições datadas do sécuIo XVI. No entanto, numa época em que se pensava que o mundo tinha sido criado há 6000 anos, elas eram vistas, apenas por curiosidade, como uma fantasia de pastores (ver Demoule 1992: 243). Ainda em França, foi um pré-historiador amador, Chiron, que, pela primeira vez, estabeleceu, na gruta de Chabot, uma relação estratigrálica entre as pinturas e as camadas arqueológicas (cf. idem: 244). Pela primeira vez, as pinturas foram consideradas paleolíticas. Mas esta descoberta passou desapercebida. As pinturas rupestres só são divulgadas como paleolíticas pelo Marquês Marcelino de Sautuola. Este investigava a gruta de Altamira perto de Santander desde 1875 , e nela descobriu pinturas que atribuiu ao paleolítico (cf. idem: 244). Mas só em 1880, depois da sua filha ter encontrado, em 1879, a famosa sala com touros policromados, é que ele publica a sua descoberta em Breves Apuntes Sobre Algunos Objectos Prehistóricos de la Provincia de Santander.

Começou então a controvérsia sobre a attenticidade das pinturas paleolíticas descobertas pelo Marquês de Santuola em Altamira (cf. idem: 244; Jorge 1995b: 364) ."Seria possivel selvagens de há 30.000 ou 20.000 anos terem feito obras de arte?" (Jorge 1995b: 364). Ou seja, seria possível que as pinturas encontradas pela filha do Marquês fossem, como este afirmava, paleolíticas? Para os intelectuais cristãos, a arte paleolítica surgia como uma prova da existência, desde épocas recuadas, de uma espiritualidade humana (ver Demoule 1992: 244). Mas, os positivistas, que, na altura, colocavam o homem do paleolítico num nível evolutivo próximo do dos primatas, duvidaram da autenticidade da arte paleolítica de Altamira, chegando, por vezes, a acusar de fraude o Marquês (cf. idem: 244). Com o tempo, alguns positivistas começaram a aceitar as pinturas 
como paleolíticas. A arte móvel já era reconhecida desde os anos 60 do século XIX como um entretenimento e uma manifestação estética embrionária, titubeante e gratuita dos homens do paleolítico (cf. idem: 244-45; Jorge 1995c: 382). Também a arte parietal paleolítica foi reduzida a uma primeira manifestação artística, desprovida de intencionalidade simbólica ou religiosa, pelos primeiros positivistas anticlericais que aceitaram a sua autenticidade. No entanto, arqueólogos, na altura, consagrados, como Salomon Reinach e Cartailhac, continuavam a rejeitar a origem paleolítica das pinturas (ver idem: 244).

Entretanto, a relação divulgada pelo Marquês de Santuola entre as pinturas rupestres e o paleolítico permitia descobrir no Sudoeste da França outras grutas com pinturas paleolíticas, e, no início do século XX, a autenticidade da arte parietal paleolítica foi definitivamente admitida no interior da arqueologia. Em 1901, o abade Breuil, que se viria a tornar num dos primeiros especialistas em arte paleolítica, publica, com Capitan, "As grutas com paredes gravadas ou pintadas na época paleolítica". Cartailhac acabou por publicar, em 1902, "Mea culpa de um céptico". Também Salomon Reinach, influenciado pela história das religiões, reconheceu a arte paleolítica, por comparação etnográfica com as sociedades primitivas de caçadores-recolectores, como uma arte mágica que procurava favorecer a captura e/ou a fertilidade e propagaçāo dos animais representados, publicando, em 1903, um artigo intitulado "A arte e a magia" (ver Jorge 1995c: 384). Neste, Reinach escreveu (cit. idem: 384): "Esta arte não era pois o que é a arte para os povos civilizados, um luxo ou um jogo; era a expressão de uma religião muito grosseira, mas muito intensa, feita de práticas mágicas e tendo como único objectivo a conquista da alimentação quotidiana". Também Breuil e Cartailhac, em La Caverne d'Altamira de 1906, diziam ver nas pinturas a manifestação de crenças e rituais ligados à magia da caça e da fertilidade, que afirmavam ainda encontrar em povos primitivos seus contemporâneos (cf. Demoule 1992: 245-6).

Quando se reconheceu a autenticidade das pinturas paleolíticas de Altamira fez-se apelo a uma noção metafísica e essencializadora de autenticidade, que tomou por puro, original e preexistente nas pinturas uma propriedade que nós lhes atribuímos. Contudo, as pinturas não são autênticas antes de serem autenticadas. Reconhecer a autenticidade da arte paleolítica é conferir-lhe uma qualidade que ela antes não possuía, ou seja, 
é autenticá-la. "Autenticar" é, segundo o Moderno Dicionário da Língua Portugulesa, "tornar autêntico, legalizar, certificar", ou seja, é um acto jurídico-social. Foi então este acto jurídico-social de autenticação que fez entrar, no início do século $\mathrm{XX}$, a arte rupestre no domínio de investigaçāo da arqueologia. Como nos diz Demoule: "L'acte fondateur de(s) (...) lieux archéologiques en a d'abord été l'autentification" (idem: 257).

Depois de a arte paleolítica ter sido autenticada, multiplicaram-se as descobertas de novas grutas com manifestações artísticas deste período (cf. idem: 245). Só a constituição social da arte paleolítica permitiria descobrir novas grutas. Estas descobertas devem ser portanto inseridas na história da arqueologia e da arte pré-histórica. Não as podemos pensar independentemente dos processos sociais e políticos subjacentes. Porém, estes processos sāo frequentemente invisibilizados nos relatos das descobertas da arte pré-histórica. Através desta estratégia narrativa, a arte paleolítica apresenta-se como um objecto que existe no mundo independentemente da vontade dos homens, tornando-se inquestionável. Demoule (idem: 266-7) diz-nos que, em 1990, em França, no decorrer das celebrações do quinquagésimo aniversário da descoberta das pinturas de Lascaux, esta descoberta surgiu, nos discursos oficiais, romanceada como um acaso em que quatro rapazes, ao perseguirem um cão pelas profundezas da terra, encontraram um "teatro intacto" de pinturas maravilhosas. Também a descoberta das pinturas paleolíticas de Altamira, arqueologicamente constituídas, é atribuída ao "olhar desprevenido" de uma criança, como forma de naturalizar o olhar que as descobriu, olhar este que, distituído de quaisquer constrangimentos socioculturais, depara-se com o mundo tal como ele é. Por exemplo, subjacente à descrição de Vítor Oliveira Jorge da descoberta de Altamira podemos encontrar esta estratégia de naturalizaçāo". "Em 1879, o espanhol Marcelino de Sautuola detectou as pinturas parietais de Altamira, em Santander; acreditou serem paleolíticas, mas quem as viu primeiro foi sua filha, que para elas chamou a

'Podemos compreender esta estratégia de naturalização através do texto no qual ela está inserida. Neste, Vítor Oliveira Jorge procura comprovar a veracidade, posta em causa. da arte parietal paleolítica de ar livre do vale do Côa através da história das resistências à autenticidade da arte paleolítica, hoje, institucionalmente reconhecida. 
atenção do pai, ocupado nas escavações da gruta. Eis como o olhar desprevenido de uma criança pode, às vezes, estar mais atento do que o de um adulto" (Jorge 1995c: 382).

Já vimos como a arte paleolítica foi interpretada pelos seus primeiros investigadores, evolucionistas, como um vestígio de homens que, concebidos como primitivos ou crianças, eram inseridos em estádios recuados do progresso civilizacional e, assim, aproximados da natureza. Seria, portanto, através do domínio da estrita sobrevivência, e não do simbólico ou do religioso, que se poderia explicar a arte paleolítica. Ela "tinha como único objectivo a conquista da alimentação quotidiana". Através de uma estrita referencialidade, nela se representavam, de uma forma naturalista, aleatória e caótica, os animais que, magicamente, se pretendia controlar. Sob influência do estruturalismo, LamingEmperaire e, sobretudo, Leroi-Gourhan desenvolvem, nos anos 60, uma interpretação simbólica da arte paleolítica e, assim, uma imagem mais humanizadora do homem pré-histórico. Segundo Leroi-Gourhan, a arte paleolítica era a expressão gráfica de um sistema simbólico dualisticamente organizado pelos princípios do feminino e do masculino. Os bovídeos (bois e bisontes) e os cavalos, que descobriu serem as figuras estatisticamente mais abundantes, ocupando uma posição central na gruta, não consistiam num mero decalque da realidade, isto é, numa representação realista dos animais outrora vistos, mas eram antes convenções gráficas ("construções retóricas") que representavam, respectivamente, o feminino e o masculino. Tratava-se de mitogramas que se inseriam num todo simbólico, coerente e integrado, delimitado pelo espaço da gruta. As figuras não se encontravam isoladas ou aleatória e desordenadamente dispostas, mas mantinham entre si, e com o seu suporte, relações topograficamente constantes. Assim, o espaço da gruta interferia no sentido e na composição das figuras que, por sua vez, 0 sacralizavam. Ao salientar o convencionalismo plástico da arte paleolítica, André Leroi-Gourhan entende-a como uma linguagem, ou seja, como uma construção retórica que a ideia de realismo obliterava. Desenvolve então uma análise estilística das representações paleolíticas de acordo com a qual as classifica. As figuras continuam, no entanto, a ser pensadas e definidas através da sua cronologia e de noçōes diacrónicas como a origem e a evolução. De facto, o estilo das figuras é interpretado, diacronicamente, como específico de uma determinada etapa da evo- 
lução e, deste modo, Leroi-Gourhan estabelece, para o paleolítico e com base em leis de evolução gráfica, um sistema de periodizações estilísticas que utiliza para classificar e pensar as representaçōes parietais.

\section{A constituição dialógica da arte parietal paleolítica do vale do Côa}

Arqueólogos portugueses inseridos na comunidade científica internacional iniciaram, em Novembro de 1994, o processo de divulgação das gravuras paleolíticas do Côa que, através de métodos de datação estilística, constituíram. Em Julho de 1995, são divulgados os relatórios das dataçōes directas das gravuras rupestres do Côa que negam a sua autenticidade paleolítica e que, assim, desacreditam os arqueólogos portugueses, acusando-os de fraude ou de incompetência (cf. Zilhão 1995b: 122). Surge, então, o confronto intertextual entre os especialistas na datação directa, ou absoluta, e os defensores dos critérios estilísticos ${ }^{5}$, que utilizam diferentes metodologias e epistemologias e, assim, diferentes referentes culturais para constituir as gravuras inscritas nas fragas do vale do rio Côa e na competição pelo espaço discursivo, pelo direito a contar a estória. “(...) uma polémica que de súbito invocava datações pretensamente obti-

- Segundo Leroi-Gourhan, a arte paleolítica evolui dos sinais rítmicos abstractos para o realismo das formas, demonstrando, assim, que o grafismo, na sua origem, é uma representaçāo abstracta e, neste sentido, está associado à linguagem (cf. Leroi-Gourhan s/d [1964]: 189-90). "Temos agora a certeza que o grafismo começa não por uma representação inocente do real, mas sim do abstracto" (idem: 189). "Estas consideraçōes permitem fazer sobressair que a arte figurativa está, na sua origem, directamente ligada à linguagem e muito mais próxima da escrita no sentido lato do que a obra de arte" (idem:190).

$s$ Foram quatro os especialistas em datação absoluta contratados pela EDP (Electricidade de Portugal) para datar as gravuras do Côa: Robert Bednarik, Ronald Dorn, Fred Phillips e Alan Watchman. No entanto, Phillips não apresentou em Julho de 19950 seu relatório à EDP a Dorn apenas estabeleceu uma tabela com a idade mínima das gravuras, nāo chegando portanto a concluir que elas não eram paleolíticas (cf. idem: 1245), pelo que estes dois especialistas se excluiram da polémica sobre a cronologia das gravuras encontradas no Côa. Bednarik e Watchman são portanto aqueles que defendem, com base em métodos de datação absoluta, que as figuras do Côa são pós-paleolíticas, aos quais se opõem aqueles que estilisticamente determinaram a origem paleolítica das gravuras, aqui representados por João Zilhão. 
das por meio de ciências ditas exactas, para rebater argumentos ditos 'estilísticos', até aqui apresentados como decisivos, mas subjectivos" (Baptista e Gomes 1995: 50)".

Baseando-se no modelo epistemológico das ciências naturais ou ditas exactas, os especialistas na datação absoluta procuram desacreditar a perspectiva estilística e culturalista sobre as gravuras do Côa, dizendo que ela não é científica e objectiva mas apenas revela as categorias culturais e a posição política dos que a defendem. Bednarik considera que nós não podemos aceder à informação cognitiva e cultural complexa codificada no sistema gráfico dos povos pré-históricos (cf. Bednarik 1996: 63) e que, portanto, os significados simbólicos, bem como os padrões estilísticos que os arqueólogos nele encontram consistem em construções cognitivas e perceptuais dos arqueólogos e não fazem parte da realidade física objectiva.

Archaeologists invent their taxonomies themselves, including those of rock art motifs. These constructs cannot be analysed scientifically because they are not real classes of entities in the physical world, they merely reflect the way archaeologists perceive Gestalts in the physical reality. The only scientist who might be interested in analysing these constructs would be the psychologists who has, for some reason, decided to study the mind of archaeologists. (...) The term analysis, in scientific sense, should be strictly

' Se aqui procuro pensar a polémica que se gerou entre dois especialistas de datação absoluta e Joāo Zilhāo (utilizador dos métodos estilísticos) em torno da datação das gravuras do Côa, isso nāo significa que todos aqueles que recorram a métodos de datação directa defendam a idade pós-paleolítica das gravuras, nem que todos os utilizadores dos métodos estilísticos afirmem a sua origem paleolítica. Na verdade, Anfónio M. Monge Soares, especialista em dataçāo directa, veio pôr em causa os trabalhos realizados por Watchman e Bednarik, e exigir, apoiando-se também na opiniāo de outros cientistas mundialmente conhecidos, um trabalho de investigação mais aprofundado (ver Soares 1995). O que procuro demonstrar é como os cientistas, que desenvolveram opiniões divergentes em relação à idade das gravuras e que aqui tomo em consideração, se socorreram, para o seu combate retórico, de argumentos que se inserem em tradiçōes e quadros epistemológicos diferentes, reproduzindo uma das fracturas que mais marcou a história da arqueologia. 
reserved for the analysis of real (rather then inagined) entities and taxonomies (idem: 65).

Ao referir-se especificamente a Zilhão, Bednarik considera que as suas interpretações e apreciações estilísticas sobre a arte rupestre do Côa consistem em formulações não falsificáveis pelas propriedades objectivas do mundo físico e, assim, em proposiçōes nāo científicas (cf. idem: 64), concluindo que: "A debate between us is as pointless as our respective epistemologies are incompatible" (idem: 64). Para desacreditar os critérios estilísticos de datação da arte rupestre, Bednarik recorre também à formulação narrativa da história da arqueologia, referindo alguns casos em que as dataçōes estilísticas das figuras rupestres se revelaram posteriormente falsas (cf. idem: 64). Bednarik acusa ainda os arqueólogos portugueses de, numa conferência realizada em Turim em Setembro de 1995, desrespeitarem os procedimentos do debate académico, transformando-o numa luta política pelo reconhecimento da autenticidade paleolítica das gravuras do Côa. "There can be no doubt that the conduct of some Portuguese and a few other archaeologists (who on several occasions turned the academic proceedings into political ralies in which chairpersons lost all control) at the event was a disgrace to the discipline and ought to be condemned by every archaeologist in the world who strives for intigrity in the discipline" (idem: 63). Zilhão é também criticado por desrespeitar as regras academicamente estabelecidas das citações bibliográficas. "Zilhão's referencing style must be unique in international archaeological publishing. His quotes are usualy from newspaper articles, press hand-outs, internal reports, private correspondance, truly obscure publications, and even non-existent publications" (idem: 64).

Em resposta aos especialistas em datação absoluta, Joāo Zilhāo (1995a e 1995b) procura desacreditar as suas conclusões, i.e., os seus discursos e dialogicamente legitimar os métodos de datação estilística e, assim, autenticar as gravuras paleolíticas do Côa através deles constituídas. Para desacreditar as conclusões daqueles especialistas sobre a origem pós-paleolítica das gravuras do Côa, Zilhão procura "pôr a nu as fragilidades teóricas e práticas dos métodos utilizados" (Zilhão 1995a: 119). "Watchman's maximum age is not directly based on the radiocarbon results he obtained but on an interpretation of those results that is based on false or unverified assumptions" (Zilhão 1995b: 154). Enquanto 
Bednarik (o seu outro interlocutor), "recorreu à análise da micro-erosão dos sulcos gravados embora, como ele próprio admitiu, o método não possa ser aplicado nos xistos do Côa, tanto por causa da sua estrutura e composição mineralógica das rochas como por causa da inexistência de uma curva de calibração local. A sua opinião sobre a cronologia recente das gravuras baseia-se apenas em critérios estilísticos e contextuais totalmente infundados" (idem: 119). Segundo Zilhão, o argumento defendido pelos arqueólogos contratados pela EDP que nega a autenticidade paleolítica das gravuras era uma opinião política, isto é, não científica, que tinha por objectivo desvalorizar as gravuras do vale do Côa e, assim, invalidar a necessidade da sua preservação, legitimando a construção da barragem projectada. Já antes de partir para o vale, Watchman afirmava que as gravuras não eram paleolíticas, oferecendo-se à EDP para o comprovar, limitando-se, posteriormente, a acomodar os dados que obteve, no terreno, a esse postulado de partida (cf. idem: 128-9)7. Também Bednarik procurou apenas demonstrar o seu pressuposto - o de que as gravuras não eram paleolíticas - e, assim, legitimar a construção da barragem.

(...) as was the case with Watchman, it seems fair to conclude that Bednarik came to the Côa essentially for two reasons: to prove himself right, that is, to find "evidence» of the correctness of his previous statements on the post-Paleolithic age of the stylistically Paleolithic petroglyphs; and to make an innovative point regarding preservation policies for rock art sites since, according to them, "if the art were to be shown to be post-Paleolithic, its importance would diminish dramatically and the controversy concening its preservation would be largely resolved» (quoted from a letter by Bednarik and Watchman offering their services to EDP's board of directors, dated March 24, 1995) (idem: 149).

'Watchman defende-se desta crítica nos seguintes termos: "It is standard scientific procedure to develop an hypothesis about the age of petroglyphs prior to conducting field work and then, methodically evaluating the observations and analyses, to substantiate or refute that supposition" (Watchman 1996: 21). 
Zilhão acusa também estes arqueólogos de, ao prosseguirem objectivos políticos, se excluírem da comunidade científica, negligenciando o seu corpus teórico e metodológico, a ética profissional e as regras academicamente estabelecidas de cooperação com os arqueólogos portugueses, o que os leva a ignorar o contexto arqueológico e geológico português no qual decorrem as suas investigaçōes, demonstrando como a investigação científica não é independente de uma rede de relações sociais e da tradição narrativa que a sustém.

This attitude of absolute rejection of the methodological and substantive achievements of mainstream archaeology and rock art research led Bednarik and Watchman to accept the condition set by EDP that their work should be carried out in total isolation from Portuguese prehistorians. Inconceivable on purely ethical terms, the acceptance of this condition turned out to be fatal also on purely scientific grounds. Had they "bothered» to follow the traditional rules of international scientific cooperation, they would have realized from the start that many expectations derived from their Australian experience were totally unreasonable in the Iberian context (idem: 153$)^{\mathrm{s}}$.

Zilhão considera que Bednarik despreza o contexto climático português quando se baseia na ausência de degradação por gelivação das figuras para negar a sua antiguidade, e recorre à formulação narrativa da história da rejeiçāo da autenticidade da arte paleolítica para o desacredi-

${ }^{x}$ Bednarik considera que esta crítica revela como Zilhão desvaloriza a validade científica de um argumento em favor da sua legitimidade política, e procura assim representar a ciência como uma entidade a-histórica, a-social, separada da comunidade científica no interior da qual ela é produzida. "As an archaeologist, Zilhão has understandable difficulties in coming to terms with the concept of blind test, referring to "consideration for colleagues' and deeming such tests 'unethical' (...). He succeeds in ilustrating the enormous chasm that exists between archaeology and science: he represents a self-corrupting paradigm that finds it is more considerate to one's colleagues (...) to allow them to be nislead by consensus opinions of established power or national paradigms, than to provide them with proper falsifiable data derived without recourse to what would be an 'acceptable finding"'(Bednarik 1996: 64). 
tar. "[I]t should be noted that the reasoning regarding frost-weathering is nothing but a restatement, almost 120 years later, of the arguments put forward by some nineteenth century French positivists to sustain that Altamira was a fraud (the art could not possibly be that old because it simply would not have been able to survive for so long)!" (idem: 140).

Ao utilizar o modelo epistemológico das ciências humanas para afirmar a autenticidade paleolítica das gravuras do Côa, Zilhão (1995b: 1356) coloca, aos especialistas em datação absoluta, questões estilísticas e culturais sobre as quais estes se abstêm de reflectir. Se a maior parte das gravuras do Côa foram feitas há menos de 100 anos, como Watchman afirma, então como se explica que em apenas duas ou três gerações se tenha perdido a memória dessa actividade? E se as representações do século XIX e XX de castelos, comboios e relógios que se encontram no vale do Côa estão assinadas e datadas, porque é que não o estāo as figuras estilisticamente paleolíticas? E, sobretudo, como é que moleiros do século XIX podiam conhecer e seguir as convenções estilísticas de uma arte que só posteriormente viria a ser descoberta pela ciência moderna? Os princípios que Bednarik utiliza para conferir cientificidade às suas investigaçōes e negar a cientificidade da arqueologia portuguesa são, segundo Zilhão, alheios à arqueologia enquanto ciência. Por exemplo, a aceitação do princípio epistemológico de Bednarik de que a ausência de dados sobre um dado fenómeno não constitui uma prova da sua inexistência, excluiria do domínio científico a arqueologia. No entanto, esta disciplina afirma-se histórica e politicamente como ciência.

If Bednarik were right in that criteria of absence cannot be accepted as scientific evidence, not only archaeology but also geology and paleontology would fall outside the scope of science. The fact, however, is that, whether Bednarik likes it or not, these are well established disciplines that have developed their own scientific methodology and, in particular, have leamed to deal with issues regarding pattems of presence and absence in terms of probability statements (idem: 144).

Depois de desmontar as conclusões dos especialistas em datação absoluta, Zilhão procura dialogicamente validar os métodos de datação estilística e, assim, conferir autoridade aos enunciados que afirmam a 
origem paleolítica das gravuras do Côa. Em resposta a Bednarik (ver atrás), ele afirma que a datação estilística da arte rupestre pode ser refutada (e portanto é científica) através do confronto estilístico com a arte mobiliária inserida no mesmo contex to arqueológico e seguramente datada, e recorre à formulaçāo discursiva da história da arqueologia para demonstrar como, no Sudoeste da Europa, a datação estilística da arte parietal paleolítica tem sido comprovada pela arte mobiliária, constituindo-se, portanto, como um método de dataçāo historicamente validado (cf. idem: 149-50). "Therefore, in what concerns this part of the world, and in the present state of our knowledge, the proper scientific stand can only be that of accepting what has been confirmed by one hundred years of research: that stylistically Upper Paleolithic engravings are indeed of Upper Paleolithic age" (idem: 150). Zilhão constitui uma narrativa histórica sobre os métodos de datação estilística que faz apelo a casos em que a datação directa por $\mathrm{C} 14$ da arte rupestre veio confirmar a cronologia que lhe tinha sido atribuída por comparação estilística com a arte mobiliária (cf. idem: 149; 152). Constituída em interacção com as estórias contadas por Bednarik, esta narrativa explica que as datações estilísticas que foram desmentidas pela dataçāo absoluta não se basearam na comparação com a arte mobiliária seguramente datada e, assim, não podem ser utilizadas para invalidar o método de datação estilística (cf. idem: 151152).

Zilhão procurou, deste modo, conferir autoridade aos métodos estilísticos através da história da arqueologia que narrativamente elaborou, definindo-os como um legado desta comunidade científica. Também António Martinho Baptista e Mário Varela Gomes aceitam os critérios estilísticos enquanto um método de datação tradicionalmente suportado pela comunidade dos arqueólogos. "Sem querermos fazer invocar argumentos de autoridade, (...), é evidente que há alguns dados adquiridos em arte pré-histórica, como aliás em qualquer outro ramo da arqueologia, e a questão dos estilos em arte rupestre (...) não poderá ser negligenciada" (Baptista e Gomes 1995: 50). Vários arqueólogos portugueses recorrem ainda à opinião de arqueólogos consagrados pela comunidade científica internacional para autenticar as gravuras paleolíticas do Côa. Como o diz Zilhão: "A atribuição da maioria das gravuras ao Paleolítico Superior que, com base em critérios estilísticos, tem sido proposta por todos os especialistas que já visitaram o sítio, deve ser consi- 
derada como um dado adquirido" (idem: 25). Mesmo Luís Raposo, que questiona a validade dos métodos estilísticos, reconhece a autenticidade paleolítica das gravuras do Côa, não apenas porque a sua tipologia paleolítica se repete ao longo da bacia do Douro permitindo inseri-las no seu contexto arqueológico, mas também "porque essa é a opinião de especialistas, portugueses e estrangeiros, que pessoalmente muito consideramos (em ciência, onde tudo carece de prova não nos impressionam demasiado os chamados "argumentos de autoridade")" (Raposo 1995: 321). Como o evocam António Martinho Baptista, Mário Varela Gomes, e Vítor Oliveira Jorge, é enquanto um discurso produzido por arqueólogos, socialmente definidos como os detentores do conhecimento sobre a arte préhistórica, que a atribuição ao paleolítico das gravuras do Côa ganha autoridade. Os primeiros afirmam que as dataçōes directas que definiram as gravuras como pós-paleolíticas apenas "lançaram alguma confusão entre o meio não arqueológico", "pois, como é (...) evidente, nenhum arqueólogo minimamente informado em arte pré-histórica, ou qualquer pré-historiador de arte, duvidaria já então da atribuição paleolítica de boa parte dos motivos rupestres, quer do Côa, quer de alguns dos seus afluentes" (idem: 50). Num texto de esclarecimento da opiniāo pública divulgado no Público e no Jornal de Notícias, Vítor Oliveira Jorge justifica as incertezas dos políticos quanto ao valor e preservação das gravuras do Côa pela sua falta de conhecimento em arte pré-histórica. "Compreendo a sua falta de conhecimento em pré-história, assim como eu assumo a minha ignorância em matérias de engenharia, e tantas outras. Mas por favor, saibam ouvir, neste caso, quem sabe do assunto, senhores engenheiros e senhores políticos!" (Jorge 1995a: 358).

A origem paleolítica das gravuras do Côa foi, portanto, estabelecida em interacção com os métodos de datação estilística, cuja autoridade lhes é conferida pela tradição discursiva da arqueologia, e em interacção com as versões alternativas que se lhe opuseram.

\section{Visualizando o modelo topográfico de Leroi-Gourhan nas fragas do rio Côa}

A própria possibilidade de visualizarmos as gravuras do Côa depende de um jogo intertextual. Os critérios estilísticos através dos quais 
as gravuras foram percepcionadas baseiam-se em tipologias artísticas, i.e., em representações visuais tipificadas, portanto, em construções retóricas anteriormente produzidas e suportadas pelos arqueólogos. Zilhão diz ver nas gravuras do Côa as convenções estilísticas que os pré-historiadores de arte estabeleceram para o paleolítico e, em particular, para o Solutrense: os corpos vistos de perfil; chifres retorcidos; linhas cérvico-dorsais sinuosas; barrigas "grávidas"; ausência de linha do chão (cf. idem: 120). Em resposta a Bednarik, Joāo Zilhāo determina outras características estilísticas das gravuras do Côa. Estas características que foram definidas como pós-paleolíticas por Bednarik, são por João Zilhāo, e na interacçāo com imagens arqueológicas constituídas, atribuídas ao paleolítico (cf. idem: 148-149). Zilhão demonstra, por exemplo, como a linha de sobreposição da anca que Bednarik assinala como não paleolítica numa das representações de cavalos do Côa, se encontra nas descrições das pinturas paleolíticas das grutas de Ekain e Niaux. Também um dos bovídeos do Côa, cujas marcas internas do focinho e a posição retorcida dos chifres levam Bednarik a afirmar que não se assemelha às figuras paleolíticas, é, por Zilhão, comparado com uma imagem de um dos bovídeos de Lascaux que apresenta as mesmas características e, assim, é definido como paleolítico. Zilhão confronta ainda a forma adelgaçada das cabeças de alguns dos bovídeos gravados nas fragas do Côa, que Bednarik diz ser uma característica pós-paleolítica, com a dos "famosos" auroques da gruta de Tête du Lion datados, por radiocarbono, de $21.500 \mathrm{BP}$ (cf. idem: 149).

No entanto, não é apenas pela comparação com as representações já constituídas da arte pré-histórica datada, mas é sobretudo através das periodizações estilísticas estabelecidas por Breuil e Leroi-Gourhan para o paleolítico, que os pré-historiadores de arte definem o estilo e, com ele, a cronologia das figuras rupestres. O que conduziu Martinho Baptista e Varela Gomes a realçarem "o facto das clássicas divisōes estilísticas (primeiro de Breuil e depois de Gourhan) terem espartilhado um pouco o próprio pensamento dos especialistas que se habituaram comodamente a inserir, numa ou noutra tese e num ou noutro estilo, as obras paleolíticas que vinham sendo reveladas" (op. cit.: 78). Como evocam estes arqueólogos, é a própria interpretação, e não apenas a cronologia e o estilo das figuras, que varia consoante a periodização estilística utilizada. A visualização das figuras rupestre configura assim, e desde logo, uma determinada interpretação da arte pré-histórica. Há, no entanto, que ressalvar que, 
nas suas investigaçōes sobre a arte pré-histórica, os arqueólogos não se limitam a reproduzir de forma passiva e exclusiva um ou outro destes modelos estilísticos e interpretativos, mas de forma processual, transformativa e dialógica recorrem a elementos de um e de outro, acrescentandothes novos critérios estilísticos. Contudo, podemos dizer, grosso modo, que, actualmente, o paradigma utilizado pelos arqueólogos para determinar o estilo, a cronologia e o significado da arte paleolítica é o de LeroiGourhan.

Foi, de facto, sob influência de Leroi-Gourhan que António Martinho Baptista e Mário Varela Gomes, num projecto aprovado pelo Instituto Português do Património Arquitectónico e Arqueológico (IPPAR), investigaram entre Setembro e Novembro de 1995 um dos núcleos de gravuras do Vale do Côa - a Canada do Inferno (cf. op. cit.: 50-52)". Nesta equipa de investigação encontravam-se, para além destes arqueólogos, o desenhador Fernando Barbosa, a designer Cristina Gaspar, e Jorge Soares de Barros que assegurou parte dos levantamentos fotográficos. Esta equipa que, em resposta às "tentativas" de datação absoluta das gravuras, tinha por objectivo "elaborar uma cronologia relativa da arte do Côa" (cf. idem: 50-51), procedeu ao levantamento por decalque das figuras do vale do Côa". Como boa parte dos motivos e, em especial, as gravuras filiformes são de muito difícil percepção, o levantamento foi

"Se nos lembrarmos que a leitura de Leroi-Gourhan sobre a arte paleolítica transformou a ideia entāo vigente do homem pré-histórico pensado como um primitivo e assim aproximado das crianças, podemos facilmente compreender que recorrer à teoria de LeroiGourhan para percepcionar e interprelar as gravuras do Côa é ver nelas um sistema mitológico complexo e, assim, ter uma visão humanizadora dos homens que na préhistória as realizaram.

10 O processo de dataçāo estilístici recone à teoria e tipos estilísticos estabelecidos por Leroi-Gourhan pois eles são ordenados cronologicamente, permitindo definir através do estilo da figura o período ao qual ela pertence. Como vimos, Leroi-Gourhan ao estabelecer a cronologia dos diferentes estilos de arte paleolítica, estruturava o seu pensamento através da história, e esta é de facto a perspectiva que ainda hoje os arqueólogos portugueses utilizam, em contraste com os do continente americano que pensam os achados através de categorias culturais e geográficas. É porquue a arqueologia europeia estrutura o seu pensamento através da história e assin da cronologia que a idade das gravuras do Côa foi tão fundamental para definir a sua importância (medida à luz da teoria arqueológica que as constituiu). 
realizado, de noite, com luz rasante artificial. "Isto permitiu-nos a detecção de inúmeros filiformes, que de outra forma jamais seriam percepcionados ou bem visualizados" (idem: 56). A percepçāo das gravuras não é, portanto, evidente, mas é construída através da sua representaçāo visual. Esta é elaborada através do decalque sobre plástico do tipo polivinilo transparente, segue um conjunto de convenções gráficas, e suporta-se nas análises estilísticas de Leroi-Gourhan que tomam o espaço onde as gravuras se inserem como parte integrante do seu significado. A percepção das gravuras do Côa permite assim naturalizar e reforçar um modelo interpretativo da arte rupestre que está associado a um contexto sociocultural particular.

Como nos dizem Baptista e Varela Gomes, num artigo de apresentação do seu trabalho, as características do suporte das gravuras são, tal como estas, decalcadas: "O trabalho fundamental é, pois, de reprodução das gravuras e dos principais acidentes dos seus suportes" (idem: 56). E, um pouco mais à frente, estes arqueólogos acrescentam ainda que: "as superfícies gravadas foram decalcadas integralmente, ou seja, mesmo áreas em reserva ou não decoradas dos painéis historiados foram delimitadas, de modo a melhor percebermos as causas que conduziram à eleição de certas zonas para suporte das manifestações artísticas" (idem: 57). Os decalques foram de seguida reproduzidos em papel vegetal através de um conjunto de convenções que permitem entender e percepcionar melhor as gravuras. Com o intuito de a difundir, esta representação foi ainda fotograficamente reduzida.

Os decalques em plástico foram seguidamente e em gabinete, transpostos em papel vegetal de 110 grs. Todas as graumas foram representadas a traço negro, com a forma exacta dos originais, enquanto que as representações das fissuras e estalamentos foram desenhadas arravés de linhas ponteadas $(0.5 \mathrm{~mm})$ e os limites dos painêis decorados por linha grossa a cheio $(1.2 \mathrm{~mm})$. Para um mais fácil manuseamento e publicação, os desenhos en vegetal, à escala natural são reduzidos fotograficamente e sem distorçāo para acetato transparente à escala $1 / 5$ (idem: 57).

Estas representaçōes das gravuras permitem ver e descobrir o que procuram estes dois arqueólogos. "[O] trabalho de decalque permitiu, 
como já afirmámos, detectar melhor as gravuras, sobretudo as constituídas por traços filiformes, mas muito em especial o seu processo de construção, as técnicas nelas utilizadas, os pormenores estilísticos, os diferentes graus de pátina ou desgaste e as estratigrafias verticais e horizontais, ou seja, as sobreposições e associações de signos" (idem: 56-7). Os decalques que, seguindo o modelo de Leroi-Gourhan, incluem e sublinham as relações topográficas entre as figuras, são, constituídos através de um modelo interpretativo particular, apresentando-se desde logo como uma forma de entender e constituir o sentido das gravuras, e, assim, de restringir as suas posteriores interpretações. Estamos perante um processo circular. É com base num determinado modelo interpretativo que se visualiza as gravuras, acabando esta visualização por confirmar o modelo utilizado. As relações topográficas entre as figuras, tornadas significativas no decalque, confirmam a importância do contexto espacial para aceder ao sentido das imagens. Varela Gomes e António Baptista, embora não estejam alheios a este facto, procuram negar o carácter representacional dos decalques que realizam e reclamam-nos como uma base objectiva para as mais diversas interpretaçōes. "Embora o decalque de um painel seja já uma interpretação, a regra fundamental num bom levantamento de arte rupestre deverá ser a da máxima objectividade e rigor. A documentação assim conseguida, que poderá até permitir leituras diferentes, manter-se-á como documento fiável para além da evolução das teorias interpretativas" (idem: 57 ).

É também na interacção com o modelo estilístico e interpretativo de Leroi-Gourhan que as imagens encontradas ganham valor. O "grande e abrupto maciço de xisto" que constitui o núcleo central das gravuras da Canada do Inferno é assim valorizado por reflectir este modelo.

Sítio fulcral da Canada do Infemo, será importantíssimo o seu levantamento rigoroso, pois a relação espacial das gravuras entre si e relativamente ao vale, talvez aqui como em nenhum outro sítio conhecido do Côa surja estruturada de uma maneira tão evidente. Como se sabe, os actuais modelos de investigação em arte paleolítica privilegiam exactamente o sentido de composição $e$ ordenamento espacial da temática rupestre gravada, pintada ou esculpida, concedendo-se grande atençāo ao tipo e particularismos do suporte, nomeadamente a sua localização, na esteira dos tra- 
balhos pioneiros de Laming-Emperaire e André Leroi-Gourhan, ao invés da escola de Breuil que sempre privilegiou as figuras "isoladas", desprezando até nos seus levantamentos muitos dos sinais complementares. Queremos com isto dizer, que não conhecemos, de momento, nenhum outro sítio no Vale do Côa, onde estes modelos de análise e experimentaçāo metodológica seja tão atractivo ao investigador; como neste notável penhasco historiado da Canada do Inferno, complementado por importantes rochas decoradas situadas a cotas superiores (idem: 56).

O que podemos perceber através desta citação, é que o modelo não é escolhido e valorizado por permitir explicar as imagens encontradas, ao contrário, são estas que se seleccionam e valorizam por confirmarem o modelo utilizado. Ou seja, o valor da descoberta está na confirmação de uma tradição científica particular.

A arte do Côa é percepcionada, interpretada e valorizada através do modelo topográfico de Leroi-Gourhan. Este apresenta-se como um universo fechado que tudo compreende e explica. Com base neste modelo, elabora-se o levantamento da localização das gravuras do Côa, realça-se a inscrição das gravuras em lugares elevados de difícil acesso e determinase, em simultâneo, a idade, o estilo e o significado simbólico das imagens assim configuradas. Esta imbricação da idade, estilo e significado permite reforçar cada um destes elementos, tornando-os inquestionáveis.

[A gravação das figuras no topo superior dos painéis] é outra das características que contribui para afirmar a idade paleolítica de grande parte da arte do Côa que, pelo facto de ser ao ar livre, não deixa como na arte das grutas, de buscar por vezes os sítios mais recônditos nos painéis, neste caso as superficies mais afastadas do solo, por vezes a cerca de seis ou sete metros de altura (idem: 69).

Tal como a inscrição das gravuras em lugares de difícil acesso (interpretada como uma forma de as esconder [ver idem:69]), também a sua difícil percepção é definida como uma característica da intencionalidade espacial paleolítica. 
Esta característica [a da localização inacessível das gravuras], (...) muito dentro da intencionalidade espacial paleolítica, prendese igualmente com o facto das próprias gravuras filiformes serem ao tempo da sua elaboração elas próprias de muito dificil percepção. (...) Existem cervideos recentemente descobertos na Canada do Inferno, tão finamente gravados (um deles com a particularidade notável dos ramos da armação se distribuirem e misturarem com as finas "nerv'turas" do xisto patinado a negro que lhe serve de suporte, criando-se um belo efeito de ilusão entre gravura e xisto; outro tão fino e numa zona tão alta do painel que está a mais de $5 \mathrm{~m}$ do solo actual) que só uma observação muito cuidada das rochas permitiu a sua descoberta (idem: 75).

A organização espacial das gravuras do Côa é então pensada como típica das convenções artísticas do paleolítico e também do seu universo simbólico. O levantamento da composição e localização das figuras não serve apenas para as datar mas também, e em simultâneo, para as interpretar. Depois de enfatizarem o difícil acesso e percepção das gravuras do vale do Côa, Varela Gomes e António Baptista escrevem o seguinte: "Com estas observações, estamos, profundamente, muito dentro do mundo espiritual dos caçadores paleolíticos, com motivações que nos escapam, mas onde o ordenamento do espaço (aberto neste caso) é completamente diferente do dos tempos pós-glaciares. // Poderemos mesmo concluir, que as gravuras e a eleição dos painéis para seu suporte são reflexo do modo como os homens paleolíticos viveram e estruturaram aquela paisagem" (idem: 75). Em síntese, inseridos na comunidade dos arqueólogos e em interacção com o modelo de Leroi-Gourhan nela dominante, eles descobriram e constituíram para o vale do Côa um conjunto de gravuras com "um estilo e uma simbólica paleolíticos" (idem: 79). Esta descoberta é inserida na história da disciplina e, através dela, considerada revolucionária. "A grande novidade da arte do Côa foi trazer para fora das cavernas e também com obras de grande qualidade, 5 mundo artísticosimbólico até então quase só encerrado no silêncio e escuridão das grutas. O próprio conceito de "arte das cavernas" deixa a partir de agora de fazer sentido e deverá ser também repensado" (idem: 79). 


\section{Conclusão}

Procurei aqui demonstrar como as gravuras paleolíticas do Côa foram constituídas por métodos, técnicas e/ou discursos de arqueólogos. Estes discursos foram produzidos no interior da comunidade científica, em interacção com discursos por ela anteriormente elaborados, difundidos e suportados, e, em particular, com os de Leroi-Gourhan, inseridos numa narrativa sobre a história da disciplina que os legitima, e respondem às versões alternativas que se lhes opõem - neste caso, aos discursos dos especialistas em datação absoluta sobre a cronologia pós-paleolítica das gravuras.

A polémica que se criou em torno das gravuras do Côa reproduz algumas das tensōes que marcaram a história da arqueologia, e em particular, da arte pré-histórica. A polémica centrou-se na datação das gravuras, revelando a importância do eixo cronológico para o quadro interpretativo da arqueologia que, na Europa, sempre esteve associada à história. Ela colocou em confronto especialistas em datação absoluta e protagonistas do método estilístico, reproduzindo a tensão entre as ciências naturais e as ciências humanas subjacente ao legado da arqueologia". Ao enfatizar a dimensão simbólica e representacional da arte pré-histórica, LeroiGourhan fez apelo ao quadro epistemológico das ciências humanas, afastando o homem do paleolítico do mundo natural, no qual o tinham inserido as anteriores interpretaçōes evolucionistas. Leroi-Gourhan não deixou no entanto de interpretar a arte rupestre através da diacronia, criando um sistema de periodizações estilísticas para a classificar.

"Falar deste confronto não significa, como jú referi (ver nota 6), que se possa traçar uma fronteira clara entre os defensores da datação absoluta e os utilizadores dos métodos estilísticos. Na verdade, este princípio de di-visão (Bourdieu 1991) deve ser relacionado e interceptado por outros, como a nacionalidade, $c$, ainda assim, todos eles na sua complexidade e interligação nāo conseguem eliminar a densidade e a imprevisibilidade de cisōes e alianças, por vezes com uma forte componente afectiva e de conhecimento interpessoal. A separação entre as ciências ditas exactas e as socias e humanas deve ser assim pensada como um princípio organizador abstracto que os actores sociais manipulam consoante os seus interesses políticos, económicos, afectivos e outros, tal como a polémica aqui analisada em tomo da datação das gravuras do Côa o demonstra. 
Foi com base nas periodizações estilísticas estabelecidas por LeroiGourhan que se determinou o estilo e, com ele, a cronologia paleolítica das gravuras do Côa. A arte do Côa é, assim, pensada como um todo organizado de símbolos que se inscreve numa paisagem sacralizada - num santuário. Ou seja, o quadro interpretativo utilizado para configurar o significado das gravuras não é independente do método de datação a que se recorre. Foi também em interacção com o modelo estilístico e interpretativo de Leroi-Gourhan que se constituiu, através do decalque sobre plástico, a representação visual das gravuras do vale do Côa que estrutura a sua (de per si difícil) percepção. Por outras palavras, como as gravuras, em especial as filiformes, são difíceis de ver, a sua percepção é facilitada e estruturada pela sua representação visual que, em interaç̧āo com o modelo topográfico de Gourhan, as insere no seu contexto espacial. A percepção das gravuras é então mediada por uma construção retórica, embora não seja a esta redutível e, assim, esbate a fronteira entre percepção e representação. É ainda sob influência do modelo topográfico de LeroiGourhan que a difícil percepção das gravuras é interpretada como característica da intencionalidade espacial paleolítica. Este modelo permitiu simultaneamente visualizar, datar e interpretar as gravuras do Côa.

Foi em interacção com a tradição discursiva da arqueologia que as gravuras paleolíticas do Côa foram datadas, representadas, percepcionadas e interpretadas, i.e, constituídas. Não podemos pensar que as gravuras paleolíticas existem lá fora no mundo, antes e independentemente da forma como foram constituídas pelos arqueólogos. Isto não é dizer que elas apenas existem nas cabeças das pessoas que as constituíram. O que pretendo dizer é, ao contrário, que o mundo ao qual acedemos não é independente da forma como, em interaç̧ão com outros, o conhecemos, tal como a rede de relações sociais na qual estamos inseridos não é independente do mundo que vamos constituindo através de uma permanente interacção com ele. A descoberta das gravuras paleolíticas do Côa ajudou a constituir, reproduzir e transformar a comunidade dos arqueólogos portugueses. Na verdade, a polémica gerada pelos achados do Côa criou cisões e alianças entre os arqueólogos. Criou um conflito entre Nelson Rebanda (que descobriu, mas não divulgou as gravuras) e Mila Simōes de Abreu (que denunciou a descoberta junto da opinião pública). Separou também aqueles que, como António Martinho Baptista, Mário Varela Gomes e João Zilhão, vieram a ocupar um papel importante 
no Parque Arqueológico do Vale do Côa, daqueles que, como Mila Simões, apenas podiam nele ocupar uma posição periférica ${ }^{12}$. Na verdade, aqueles arqueólogos cuja versão sobre as gravuras do Côa veio a ser autorizada, passaram a ocupar lugares politicamente relevantes no interior da comunidade arqueológica portuguesa. João Zilhão, depois de ter deixado a presidência do Parque Arqueológico do Vale do Côa, passou a presidir o Instituto Português de Arqueologia (ele próprio inexistente antes da polémica). António Martinho Baptista veio a ser o responsável pelo Centro Nacional de Arte Rupestre, também só criado depois dos acontecimentos do Côa. Vítor Oliveira Jorge viu reforçada a sua já anterior posição de prestígio e consenso como presidente da Sociedade Portuguesa de Antropologia e Etnologia ${ }^{13}$.

É porém importante salientar que as comunidades científicas não vivem isoladas, separadas do contexto económico e sociopolítico mais vasto a que pertencem. Os discursos dos arqueólogos são influenciados e influenciam espaços socioculturais que não se circunscrevem ao meio académico. Este fenómeno ganha uma maior amplitude e torna-se especialmente evidente no caso, aqui em apreciação, dos discursos sobre o património arqueológico do Côa, já que a preservação deste património colidia com a construção de uma barragem (nacional e localmente) projectada, razão pela qual se tornou objecto de um debate público, ampla e intensamente difundido e produzido pelos diferentes órgãos de comunicação social. A arqueologia, veio a ter, depois destes acontecimentos, uma visibilidade e uma projecçāo públicas que até aí não tinha. Multiplicaramse então pelo país lugares e circuitos associados ao turismo arqueológico. Por outro lado, ainda antes de se estabelecer cientificamente um consen-

12 Como presidente da Federação Internacional de Organizações de Arte Rupestre, Mila Simōes de Abreu organizou em 1998 um Congresso Internacional de Arte Rupestre na Universidade de Trás-os-Montes e Alto Douro. Nenhum elemento do Parque Arqueológico do Vale do Côa ou do recém criado Instituto Português de Arqueologia esteve presente nesse congresso.

${ }_{13}^{3}$ Não incluo aqui o nome de todos aqueles que, de uma forma ou de outra, viram, depois dos acontecimentos do Côa, mudar a sua posição no interior da comunidade dos arqueólogos e face à comunidade portuguesa. Apenas refiro aqueles que mediaticamente mais se destacaram e, sobretudo, os arqueólogos cujos discursos foram neste artigo analisados. 
so sobre a cronologia das gravuras, já se decidira em Março de 1996 e por Resolução do Conselho de Ministros criar o Parque Arqueológico do Vale do Côa, e assim a polémica em torno da cronologia foi politicamente encerrada.

\section{Agradecimentos}

Agradeço os comentários e sugestōes dos referees e também a Luís Quintais. Todos os eventuais erros e omissões são da minha inteira responsabilidade.

\section{Bibliografia}

Baptista, A. M.; Gomes, M. V.1995. A Arte Rupestre do Vale do Côa. 1. Canada do Inferno. Primeiras Impressões. In Jorge, V. O. (coord.). Dossier Côa. Porto, Sociedade Portuguesa de Antropologia e Etnologia: 45-118.

Bednarik, R. G. 1996. Côa Debated at Last! In Rock Ant Research,13 (1): 6366.

Bourdieu, P. 1991. La Domination Masculine. In Actes de la Recherche en Sciences Sociales, 84: 2-31.

Bruner, E.M. ; Gorfain, P. 1984. Dialogic Narration and the Paradoxes of Masada.

In Bruner, E.M. (Ed.). Text, Play, and Story-The Construction and Reconstruction of Self and Society. Illinois, Waveland Press: 56-75.

Classen, C. 1993. Worlds of Sense; Exploring the Senses in History and Across Cultures. Londres, Routledge.

Demoule, J-P. 1992. Lascaux. In Nora, P. (Dir.). Les Lieux de Mémoire. III-Les Frances (3). Paris, Gallimard: 237-270.

Jorge, V. O. 1995a. Por que é que o Património Cultural do Côa Não Pode Ir por Água Abaixo? In Jorge, V. O. (coord.). Dossier Côa. Porto, Sociedade Portuguesa de Antropologia e Etnologia: 355-360.

Jorge, V. O. 1995b. Património do Côa: Novo Esclarecimento à Opinião Pública. In Jorge, V. O. (coord.). Dossier Côa. Porto, Sociedade Portuguesa de Antropologia e Etnologia: 361-366.

Jorge, V. O. 1995c. Côa: Cosmos ou Caos? In Jorge, V. O. (coord.). Dossier Côa. Porto, Sociedade Portuguesa de Antropologia e Etnologia: 379-386. 
Leroi-Gourhan, A. s/d (1²Ed. 1964). O Gesto e a Palavra. 1-Técnica e Linguagem. Lisboa, Edições 70.

Lexicotexa - Moderno Dicionário de Língua Portuguesa. 1985. Volume 1/ A-L. Lisboa, Círculo de Leitores.

Merleau-Ponty, M. 1945. Phénoménologie de la Perception. Paris, Gallimard. Raposo, L. 1995. A Verdadeira Importância das Gravuras do Côa. In Jorge, V. O. (coord.). Dossier Côa. Porto, Sociedade Portuguesa de Antropologia e Etnologia: 319-322.

Soares. A. M. M.1995. Os métodos de "Datação Directa" Aplicados no Côa. In Jorge, V. O. (coord.). Dossier Côa. Porto, Sociedade Portuguesa de Antropologia e Etnologia: 95-203.

Stoller, P. 1989. The Taste of Ethographic Things: the senses in antiropology. Philadelphia, University of Pennsylvania Press.

Xavier, S. 1999. Acerca da Visibilidade do Lugar: Experiência e Representação do Vale do Côa. Tese de mestrado. Lisboa, Departamento de Antropologia da Faculdade de Ciências Sociais e Humanas da Universidade de Lisboa.

Xavier S. 2000. O Monumento é o Vale: o Parque Arqueológico do Côa e a Retórica da Paisagem. In Etnográfica: Revista do Centro de Estudos de Antropologia Social, IV (1): 109-127.

Zilhão, J. 1991. Sobre a Relação entre Teoria e Prática em Arqueologia Préhistórica Boletín de Antropologia Americana, 23: 47-66.

Zilhão, J. 1995a. Política e Ciência na Questão do Côa. In Projecto Património, 2: 25-27.

Zilhāo, J. 1995b. The Stylistically Paleolithic Petroglyphs of the Côa Valley (Portugal) are of Paleolithic Age. A Refutation of their "Direct Dating" to Recent Times. In Jorge, V. O. (coord.). Dossier Côa. Porto, Sociedade Portuguesa de Antropologia e Etnologia: 119-166.

Watchman, A. 1996. A Review of the Theory and Assumptions in the AMS Dating of the Foz Côa Petroglyphs, Portugal. In Rock Art Research, 3 (1): 21-30. 